\title{
AC 2012-4263: EXAMINING THE EFFICACY OF A LEGO ROBOTICS TRAINING FOR VOLUNTEER MENTORS AND K-12 TEACHERS
}

\author{
Ms. Irina Igel, Polytechnic Institute of New York University
}

Irina Igel received a B.S degree in mathematics with a minor in computer science from NYU-Poly, Brooklyn, NY, in 2009. Upon graduating, she received an Adjunct Instructor position at the Department of Mathematics at NYU-Poly, teaching undergraduate math courses to incoming freshmen. She is currently serving as a teaching Fellow at the Bedford Academy HS under NYU-Poly's GK-12 program funded by NSF and CBSI consortium of donors. She is perusing a M.S. degree in mechanical engineering with emphasis on control and dynamical systems. Her research interests include cooperative control of multi-agent systems, flocking, and shoaling behavior in live animals, and distributed consensus algorithms analysis and computation.

\section{Mr. Ronald Leonel Poveda, Polytechnic Institute of New York University}

Ronald Poveda received a B.S. degree in mechanical engineering, summa cum laude, from NYU-Poly in 2009. Upon graduation, he started research for a Ph.D. degree in mechanical engineering in the Composite Materials and Mechanics Lab. He is currently serving as a teaching Fellow at the Mott Hall Bridges Academy under NYU-Poly's GK-12 program funded by NSF and CBSI consortium of donors. In the summer of 2008, he held a mechanical engineering internship position with Motorola, Inc., performing mechanical testing and evaluation of scanners and other mobile devices in Holtsville, N.Y. His largely experimental research is focused on parametric studies of novel lightweight composites and simulations of functionally graded materials under load.

\section{Dr. Vikram Kapila, Polytechnic Institute of New York University}

Vikram Kapila is a professor of mechanical engineering at NYU-Poly, where he directs an NSF funded Web-Enabled Mechatronics and Process Control Remote Laboratory, an NSF funded Research Experience for Teachers Site in Mechatronics, and an NSF-funded GK-12 Fellows project. He has held visiting positions with the Air Force Research Laboratories in Dayton, Ohio. His research interests are in cooperative control; distributed spacecraft formation control; linear/nonlinear control; and mechatronics. Under Research Experience for Teachers Site and GK-12 Fellows programs, funded by the National Science Foundation, and the Central Brooklyn STEM Initiative (CBSI), he has conducted significant K-12 outreach to integrate engineering concepts in science classrooms and labs of several New York City public schools. He received Polytechnic's 2002, 2008, and 2011 Jacobs Excellence in Education Award and 2003 Distinguished Teacher Award. In 2004, he was selected for a three-year term as a Senior Faculty Fellow of NYU-Poly's Othmer Institute for Interdisciplinary Studies. His scholarly activities have included three edited books, six chapters in edited books, one book review, 47 journal articles, and 97 conference papers. Moreover, he has mentored 82 high school students, more than $300 \mathrm{~K}-12$ teachers, 22 undergraduate summer interns, and 11 undergraduate capstone-design teams, and graduated eight M.S. and four Ph.D. students.

\section{Dr. Magued G. Iskander P.E., Polytechnic Institute of New York University}

Magued Iskander is a Professor and Graduate Adviser of the Civil Engineering Department at NYU-Poly. Dr. Iskander is a recipient of NSF CAREER award, Chi Epsilon (Civil Engineering Honor Society) Metropolitan District James M. Robbins Excellence in Teaching Award, Polytechnic's Distinguished Teacher Award, and NYU-Poly's Jacobs Excellence in Education Award (twice). Dr. Iskanders research interests include Geotechnical modeling with transparent soils, foundation engineering, and urban geotechnology. He makes extensive use of sensors and measurement systems in his research studies. Dr. Iskander has published 10 books, 100 papers, and graduated 6 doctoral students, 27 masters students, 12 undergraduate research assistants, and supervised the research activities of 3 school teachers and 9 high school students. 


\section{Examining the Efficacy of a LEGO Robotics Training for Volunteer Mentors and K-12 Teachers}

\section{Introduction}

The uses and effectiveness of technology that help shape children's understanding of science and engineering were studied in literature as early as Papert's seminal work ${ }^{1}$ on constructivism. Papert showed that learning to use computers from an early age helps shape the way children think of, learn with, and understand computers and even other disciplines, such as math. In the years following Papert's work, many uses of engaging, modern technologies (e.g., sensors, gaming, and robotics) were examined to develop K-12 students' learning, understanding, and interest in science, technology, engineering, and math (STEM) subjects. ${ }^{2-11}$ For example, use of LEGO Mindstorms-based automated lab apparatus and mobile robotic activities have been shown to enhance students' understanding of science and mathematics. ${ }^{12-15}$ Similarly, for over a decade, robotics competitions, such as FIRST LEGO League (FLL), have served as a bridge between K-12 science and math classrooms and the world of exploration, engineering, and technology.

Teachers' attitudes and beliefs about the importance of Design, Engineering, and Technology (DET) mostly come from their classroom experience. ${ }^{16,17}$ Quantitative analysis ${ }^{16}$ has shown that K-12 teachers think that implementation of DET in the classroom is important; however, their rating of self-familiarity with DET is low. Hence, with proper education relating to the use and benefits of educational technologies, teachers can be expected to be more prepared to implement technology in the classroom. ${ }^{18}$ Teacher readiness and professional education require significant effort to facilitate integration of engineering and technology content in the teaching of science and math. ${ }^{19,20}$ Several papers focusing on the use of robotics in STEM education have explicitly acknowledged the challenge of teacher preparation. For example, teacher training has been identified as one of the main challenges preventing the adoption of robotics in STEM education. ${ }^{5}$ Moreover, teachers often find it difficult to link robotic activities to the curriculum outcomes. ${ }^{7}$ Finally, if teachers are not comfortable with the robotics material, then the project implementation and sustainability may suffer. ${ }^{21}$ Thus, it is evident that the sustainability of robotics-based activities in K-12 STEM education is strongly tied to the quality of teacher professional development programs.

Literature on professional development suggests ${ }^{17}$ that teachers sustain more skills from professional development which (1) expands their knowledge and skills, (2) offers a practical curriculum with direct applicability in the classroom environment, and (3) enhances their effectiveness with students. Moreover, successful professional development activities are designed to initiate change in teachers' attitudes, beliefs, and perceptions. ${ }^{17}$ To this end, use of 
LEGO Mindstorms in teacher professional education offers a multi-purpose tool that teachers can exploit immediately following their training to help teach and build students' STEM skills not only through FLL contests but also through integration of hands-on scientific inquiry, mathematical analysis, and engineering design activities in the classroom. With a multitude of literature, textbooks, and online user-guides, ${ }^{2-24}$ one may perceive that it ought to be straightforward for teachers to exploit the various resources to practice, integrate, and implement LEGO Mindstorms-based STEM learning activities in their classrooms. In practice, however, teaching STEM concepts, especially technology and engineering, through LEGO Mindstorms requires a certain level of teacher's engineering self-efficacy, which can only be gained through deliberate practice and engineering experience. ${ }^{25-27}$ Over the years, engineering education

researchers have developed a variety of instruments to measure engineering self-efficacy. ${ }^{28-30}$ These measurement instruments are often used to examine an individual's drive for engineering and need for additional pedagogical support, as well as a basis to group individuals for design projects. ${ }^{28}$ For K-12 teachers, engineering self-efficacy may be gained and sustained through well-designed LEGO Mindstorms-based training that takes into consideration teachers' prior skills and engineering self-assessment.

In this paper we examine the effectiveness of LEGO robotics training and user-guides in enabling teachers to build, program, and operate robots, skills that can enable them to create and sustain LEGO Mindstorms-based activities for formal STEM education. We present the results of a study that utilized low-intensity resources (e.g., a short training workshop, user-guides, and building and programming instructions) to assess the skills gained by K-12 mentors and teachers with varied levels of education, teaching, and prior robotics expertise. Specifically, to analyze the effect of training and user-guides on introducing and developing participants' skills in robotics design activities, a LEGO Mindstorms workshop was offered to a group of volunteer FLL mentors and K-12 teachers. Using self-efficacy and engineering design performance instruments, we examine whether the hurdle of learning to use LEGO Mindstorms is too high for teachers with non-engineering background. Participants' ability to sustain learned skills is examined through their individual performance in a designated robotic design challenge and their responses to a workshop assessment survey. In addition, we offer an analysis of the effects that academic and professional backgrounds and gender have on participants' engineering design performance. The following sections provide: the description of training, research design and data collection methods, assessment analysis, and discussion and conclusions.

\section{Training Description}

\subsection{Recruitment of Participants}

For this study, a LEGO Mindstorms robotics workshop was offered to 1) a group of volunteer student mentors, who pursued mostly STEM majors for their undergraduate or 
graduate degrees; and 2) K-12 teachers with mostly non-engineering educational background. Both groups had limited to no experience working with LEGO Mindstorms robotics. The volunteer mentors who participated in the training had been assigned to serve as coaches for FLL teams in the New York City (NYC) K-12 schools. The training workshop for these mentors was mandatory and they were recruited by the New York Academy of Sciences, which offers opportunities to STEM students at local colleges to serve as volunteer mentors in K-12 schools. These volunteers consisted of associate, bachelor, masters, and doctoral degree students, some of whom had recently graduated, who needed training in LEGO Mindstorms prior to beginning their mentoring assignments as FLL coaches. Most mentors identified themselves as having STEM-related academic background, such as neuroscience, computer science, and engineering. Some mentors indicated prior experience working with youth in afterschool programs.

The K-12 teachers were reached through email advertisements about a free training workshop for teachers with no prior experience in robotics. The email advertisement was sent to over 200 teachers, principals, and school district administrators within the NYC area. It emphasized that the workshop will help teachers (1) enrich the classroom time with engaging, student-friendly LEGO Mindstorms-based STEM activities; (2) learn to design and build robotic devices as an engineer; (3) learn the use of LEGO Mindstorms sensors for creating inquiry-based lab activities; and (4) learn to program using LEGO Digital Designer and LEGO Mindstorms software. The teachers who signed up and attended the training were a group of self-selected individuals with interest to either enrich their classroom time with robotics activities or improve their engineering and programming skills to coach their school's FLL teams.

All workshops took place on weekends and lasted six hours, with one hour break for lunch. Specifically, four workshops were hosted at the Polytechnic Institute of NYU (NYUPoly): one workshop for 17 volunteer FLL mentors on September 24, 2011, and three workshops for 25 K-12 teachers from NYC schools, on November 19, December 10, and December 17, 2011. Among volunteer mentors, 8 (47.1\%) participants majored in engineering in college or graduate school, 3 (17.6\%) majored in science, technology, or mathematics, 1 (5.9\%) majored in social sciences, $1(5.9 \%)$ majored in education, and $4(23.5 \%)$ did not provide academic background information (see Appendix: Table A1, Q1). Similarly, among teachers, 13 (52\%) participants majored in science, technology, or mathematics in college or graduate school, $6(24 \%)$ majored in education, and $6(24 \%)$ majored in social sciences. The gender breakdown was $5(29.4 \%)$ females and $12(70.6 \%)$ males among volunteer mentors, $16(64.0 \%)$ females and $9(36.0 \%)$ males among teachers, and 21 (50.0\%) females and 21 (50.0\%) males overall.

\subsection{Training Content}

All workshops offered an identical, one-day curriculum that was designed to allow participants to learn and practice basic robot building and LEGO Mindstorms programming 
skills. Moreover, the workshops introduced necessary resources and guides to participants so that they could effectively utilize the allotted time of the workshop and sustain the use of LEGO Mindstorms. The building and programming user guides and resources were made available to workshop participants through nxtprograms.com web service, LEGO Digital Designer, and computer-aided design software. The LEGO Digital Designer models and corresponding building instructions were developed by training coordinators prior to the workshop. Following the workshop, all participants were given access to all of the presented material through the Dropbox cloud storage service. During the workshop, various elements of curriculum were introduced in the following order: (1) uses and functions of NXT, sensors, and motors in the LEGO Mindstorms kit (lecture); (2) use step-by-step instructions to build a mobile robot base and integrate sensors in the design, see Figure 1(a) (hands-on); (3) learn to create programs to operate motors and obtain sensor measurements (lecture and hands-on); (4) learn concepts of mechanical advantage, gear ratios, and various robot construction tips (lecture); (5) learn the design of passive and powered attachments (lecture); (6) calibrate a light sensor mounted on a mobile robot to follow a line using a given LEGO Mindstorms program (lecture and hands-on); and (7) apply and demonstrate newly attained skills in a final building and programming challenge (hands-on).

\subsection{The Building and Programming Challenge}

In the final component of the training workshop, which lasted 90 minutes, the participants were challenged to design and build a robot that had to drive from a starting position to a stationary object, which was placed at the end of a path outlined by a black tape. The robot was required to grab the object and bring it back to the starting position. The main requirements of the challenge included: (1) the robot had to be mobile during the challenge, it needed to be programmed to move autonomously; (2) the robot had to use sensors to determine proximity to the object on its path; and (3) the robot had to have an attachment to grab the object and be able to travel without losing the object from its grip. The user guides introduced during the training were perceived to be useful since teachers were observed to consult them extensively while conducting research, design, and implementation activities for the challenge. Figure 1(b) shows a team of workshop participants working on the robot during the final challenge. Figures 1(c), (d) illustrate two prototype robots built by K-12 teachers during the final challenge.

\section{Research Design and Data Collection Methods}

To understand how volunteer mentors and K-12 teachers approach an engineering design-based project, three types of assessment data was collected in this study: 1) assessment of self-efficacy, 2) assessment of engineering design process implementation, and 3) assessment of training quality. The assessment of self-efficacy was implemented only among K-12 teachers and is used to compare how the self-perception of engineering skills influences the hands-on 
implementations during the robotic design challenge. The study assesses the difficulty of learning to use LEGO Mindstorms among participants with engineering and non-engineering backgrounds. This is achieved by grading and comparing engineering design implementation of volunteer mentors and teachers during the final challenge of training. The assessment of training quality is used to compare the perception of learning between volunteer mentors and teachers.

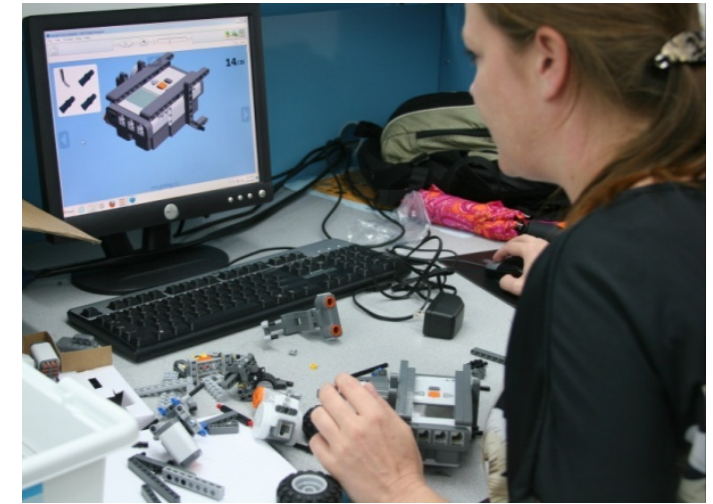

(a)

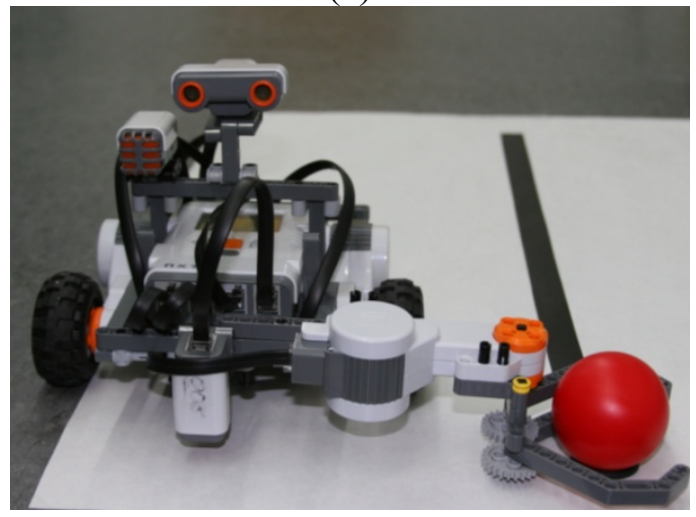

(c)

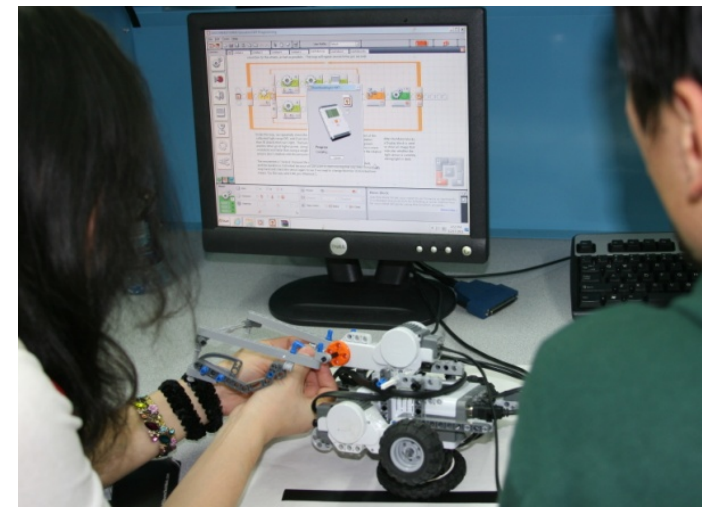

(b)

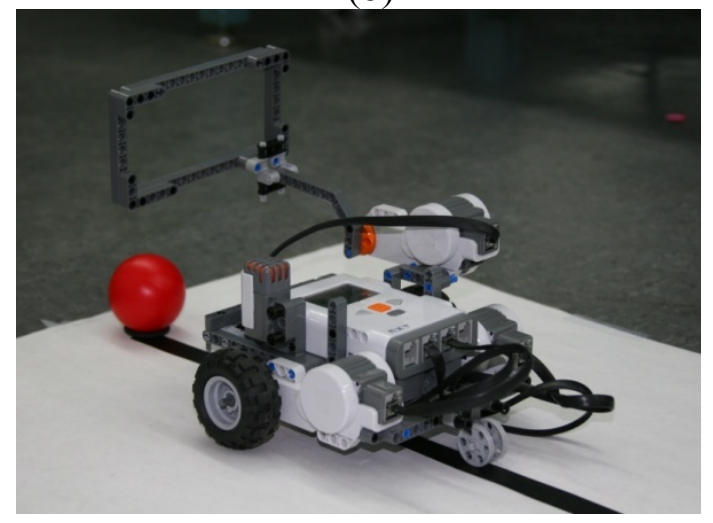

(d)

Figure 1: (a) A volunteer FLL mentor building a LEGO Mindstorms robot using the LEGO Digital Designer instructions; (b) A team of teachers working on the challenge part of the training; and (c) and (d) Examples of LEGO Mindstorms robots built by K-12 teachers with no prior experience with robotics for the challenge part of the training.

\subsection{Self-efficacy Assessment}

To measure individual K-12 teacher's will to persist and skill to succeed, a 36-item instrument, adopted from Ref. 28, was used. The self-efficacy instrument ${ }^{28}$ was designed to measure an individual's confidence, motivation, outcome expectancy, and apprehensiveness to implement the eight-step Engineering Design Process (EDP) ${ }^{31}$ shown in Figure 2. It is pertinent to recall two notable outcomes of the study in Ref. 28: (1) the self-efficacy instrument (Table A2) is proved to be highly reliable and (2) "confidence, motivation, outcome expectancy, and anxiety toward engineering design match an individual's level of engineering design self- 
efficacy." In this effort, the self-efficacy survey was distributed only among teachers and not the mentors, and it was collected before conducting any lessons or hands-on activities of the workshop. The teachers used an 11-step response scale from 0 to $100 .{ }^{28}$ As indicated in Ref. 28, the 0-100 scale is known to yield a stronger performance indicator than a five-point Likertscale $^{32}$ and teachers and graders have a better understanding of it due to its widespread use in grading exams. The survey was not mandatory and took an average of five minutes to complete. Individual surveys with incomplete entries or surveys where each item was rated with the same score were excluded from further consideration for analysis, following standard practice. ${ }^{28}$ Finally, the training described in subsection 2.2 provided a mechanism to expose participants to the various steps of the EDP.

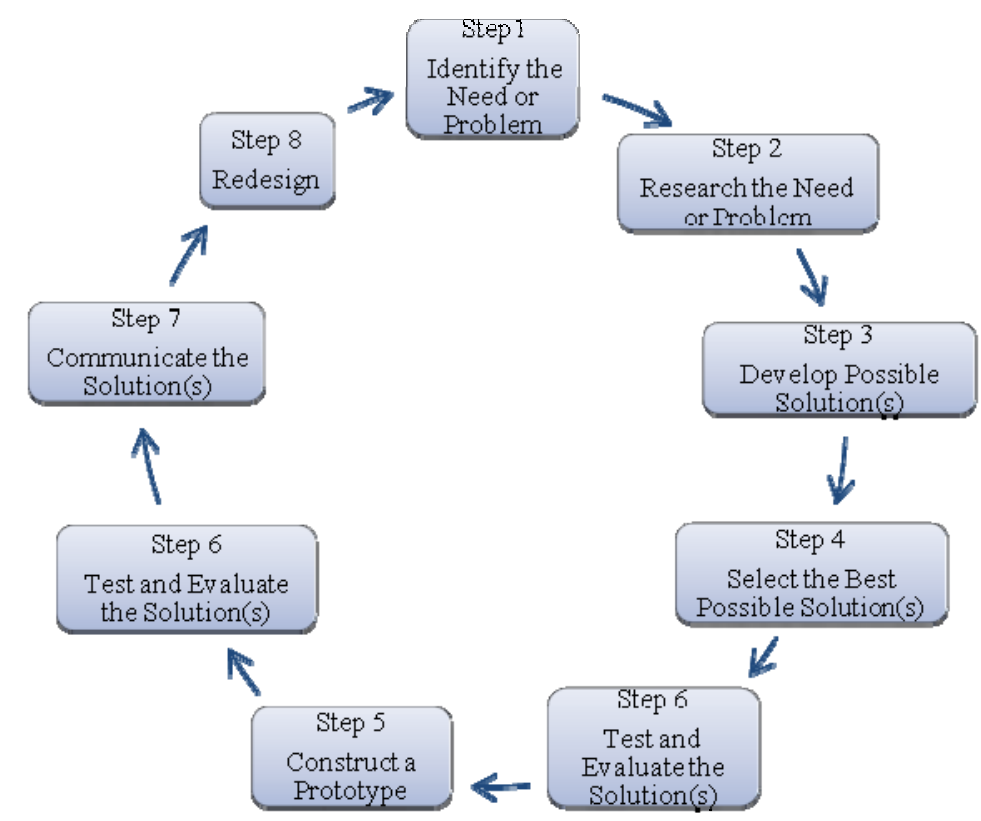

Figure 2: The eight-step Engineering Design Process. ${ }^{31}$

\subsection{Assessment of Engineering Design Process Implementation}

To examine each individual participant's ability to follow and apply the engineering design process, the design challenge part of the training was graded using the rubric given in Table 1. To make the grading process easy to conduct and keep it as unbiased as possible, the process and progress of building and programming a robotic device was video recorded for each participant throughout the design challenge. Two NYU-Poly mechanical engineering graduate students used the video footage to evaluate the design process of each attendee using a response format on an 11-step scale from 0 to 100, which was chosen to correspond to the response format that attendees used on the engineering self-efficacy survey. ${ }^{28}$ 


\subsection{Assessment of Training Quality}

Table A1 shows four survey questions that were asked to ascertain participants' academic background $(\mathrm{Q} 1)$, teaching experience and expertise $(\mathrm{Q} 2)$, experience in building and programming with robotics $(\mathrm{Q} 3)$, and prior experience with mentoring robotics teams $(\mathrm{Q} 4)$. In addition, Table A1 shows five questions that were asked to obtain participants' quantitative feedback on the overall quality of the workshop (Q5), their skills and knowledge prior to and after the workshop (Q6, Q7), and the effect that the workshop had on their robot building and programming skills (Q8-Q9). More specifically, questions 6 and 7 assessed participants' perceived learning, and questions 8 and 9 assessed the extent to which participants changed their attitude and skill toward robot building and programming. Using the Likert-scale response method, the participants responded to Questions 5-9 that were formulated using two of the four levels of questions suggested by the Reaction and Learning levels of Kirkpatrick. ${ }^{33}$ The Likertscale was quantified in ascending order, such that "Poor" $=1$ and "Excellent" $=5$. The training quality survey was distributed among both volunteer mentors and K-12 teachers.

Table 1: Grading rubric used to assess the engineering design process implementation.

\begin{tabular}{|c|c|c|c|c|c|}
\hline 0 & 20 & 40 & 50 & 70 & 100 \\
\hline No effort & Poor & Insufficient & Sufficient & Good & Excellent \\
\hline $\begin{array}{l}\text { A person did not } \\
\text { follow EDP. The } \\
\text { device did not } \\
\text { incorporate any of } \\
\text { the necessary } \\
\text { requirements set by } \\
\text { the challenge. }\end{array}$ & $\begin{array}{l}\text { A person followed a } \\
\text { few steps of EDP. A } \\
\text { person showed little } \\
\text { systematic approach } \\
\text { during the design. } \\
\text { The device met } \\
\text { limited amount of } \\
\text { requirements set by } \\
\text { the challenge. }\end{array}$ & $\begin{array}{l}\text { A person followed } \\
\text { some steps of EDP } \\
\text { and showed some } \\
\text { type of systematic } \\
\text { organization during } \\
\text { design. The device } \\
\text { met reasonable } \\
\text { amount of } \\
\text { requirements set by } \\
\text { the challenge. }\end{array}$ & $\begin{array}{l}\text { A person followed } \\
\text { most steps of EDP } \\
\text { and showed a } \\
\text { notable } \\
\text { consideration for } \\
\text { systematic approach } \\
\text { during the design } \\
\text { challenge. The } \\
\text { device fulfilled } \\
\text { most requirements } \\
\text { set by the challenge. }\end{array}$ & $\begin{array}{l}\text { A person followed } \\
\text { all steps of EDP. A } \\
\text { mostly systematic } \\
\text { approach was } \\
\text { chosen during the } \\
\text { design challenge. } \\
\text { The device fulfilled } \\
\text { nearly all } \\
\text { requirements set by } \\
\text { the challenge. }\end{array}$ & $\begin{array}{l}\text { The person followed } \\
\text { all steps of EDP in } \\
\text { designing their } \\
\text { device. A person } \\
\text { went above and } \\
\text { beyond of what was } \\
\text { required by the } \\
\text { challenge and } \\
\text { shown outstanding } \\
\text { creativity. All EDP } \\
\text { steps were followed } \\
\text { in the systematic } \\
\text { order. }\end{array}$ \\
\hline
\end{tabular}

\section{Assessment Analysis}

\subsection{Significance Analysis of Survey Responses}

Out of the 25 teachers who attended the training, 4 chose not to fill out the self-efficacy survey, 3 rated most items with the same scores and had to be excluded from analysis, and 1 did not fill out the survey completely. The results in Figure 3(a) show the average and standard deviation of responses for the remaining 17 teachers to the engineering design self-efficacy instrument. Similar to the results in Ref. 28, confidence, motivation, outcome expectancy, and apprehension toward EDP is consistent with engineering design, even for a small sample of 17 teachers. Moreover, mean and standard deviation of engineering design scores for motivation and outcome expectancy for the sample of 17 teachers was found to match the mean and 
standard deviation of engineering design scores for the larger pool of non-engineers with science backgrounds given in Ref. 28.

Figure 3(b) provides results for the average and standard deviation of scores given by the two graduate student graders for the final design challenge of the training workshop. The figure compares graded scores of 17 volunteer student mentors, 25 K-12 teachers, and, additionally, provides scores for a subset of teachers whose self-efficacy survey responses are summarized in Figure 3(a). The inter-rater reliability between the two graders was assessed using Cohen's kappa statistic with quadratic weights. To perform the test, grades were classified by 2 factors (Grader 1 and Grader 2$)$ and 11 categories $(0,10,20, \ldots, 90,100)$. The true population kappa statistic was found to be in $0.70 \pm 0.15$ confidence interval with $95 \%$ confidence, revealing that there is a "substantial agreement" between the two graders on the engineering design performance of each teacher. ${ }^{34,35}$ The $p$-value for rejecting the null hypothesis, that agreement between the graders is no better than chance when it is in fact true, is less than 0.0001 .

According to the assessment of the training quality (Q5, Table A1), the average rating of the training lies in the $95 \%$ confidence interval $4.43 \pm 0.20$, where the sample mean is averaged over all 42 attendees. Volunteer mentors and K-12 teachers were in agreement over the rating of the training with average scores of 4.35 given by the volunteer mentors and 4.48 given by the K12 teachers. Figure 3(c) shows the average rating and standard deviation of the building and programming skills (Q6-Q7, Table A1) that the volunteer mentors and K-12 teachers believed to have attained during the training. The ratio of attained robotics skills to programming skills was approximately 0.97 and 1.01 among the volunteer mentors and K-12 teachers, respectively. Figure 3(d) shows the average rating and standard deviation of the overall level of engineering design skill before and after the training among the volunteer mentors and K-12 teachers. A test was conducted at the $95 \%$ confidence level to determine the scale of perceived improvement before and after the training. Participants from the group of volunteer mentors perceived that their skills improved on average by $1.29 \pm 0.54$ on the Likert-scale. Participants from the group of K-12 teachers perceived that their skills improved on average by $1.84 \pm 0.37$ on the Likert-scale.

\subsection{Background-dependent Analysis}

To analyze the effect of prior experience and gender on teachers' learning, the attendees were partitioned into three categories: academic background (Q1, Table A1), teaching background, (Q2, Table A1), and gender. Table 2 provides a background- and gender-specific analysis of graded engineering design performance with $95 \%$ confidence interval for true mean estimation of the scores. The background-dependent analysis in Table 2 was conducted for 25 and 23 teachers who provided their academic and teaching background information, respectively. Since the number of volunteer mentors with non-STEM background was too small to produce statistically meaningful results, no background-dependent analysis was conducted for volunteer 
mentors. An unpaired two sample $t$-test ${ }^{36}$ with unequal variances was conducted to measure differences in performing graded engineering design between genders. The test indicated that the differences were not significant at 10\% level among the volunteer mentors $(p=0.917)$, teachers ( $p=0.146)$, and overall $(p=0.104)$. A two-sided, paired difference $t$-test ${ }^{37}$ was conducted to compare consistency between teachers' self-efficacy (EDP confidence) and graded engineering design performance, see Table 3. The test was conducted for 17 teachers who answered the survey in Table A2 completely and did not rate each item with the same score. According to Table 3, teachers who majored in science, technology and math, and teachers those who teach in high schools are more likely to have differences between perceptions of self-efficacy and their graded engineering design performance. Teachers who majored in education and social sciences, and teachers who teach in elementary and middle schools showed no significant difference between their self-efficacy perception and engineering design performance.

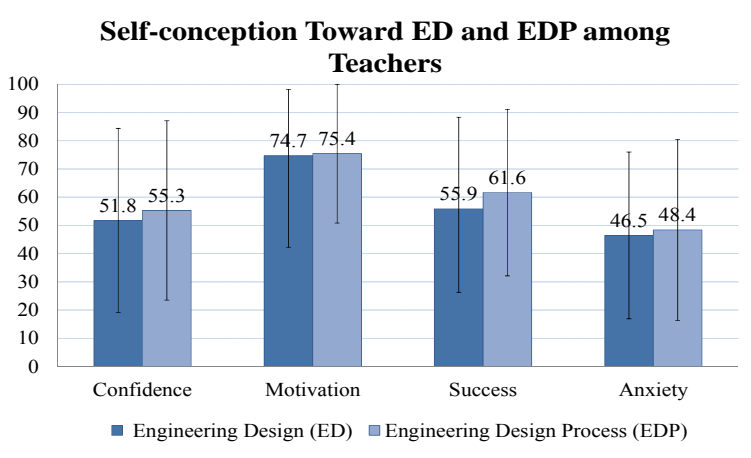

(a)

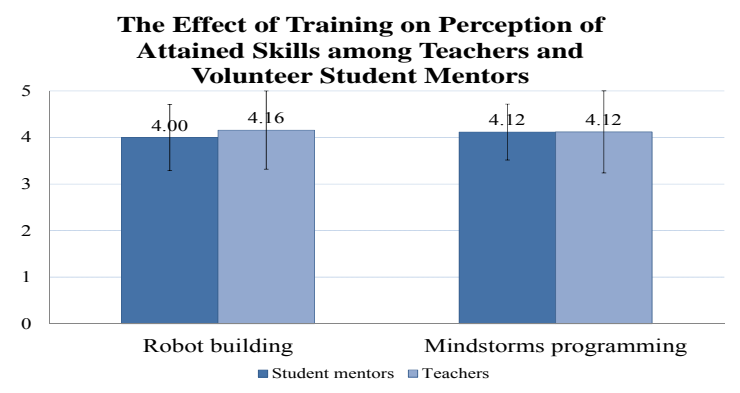

(c)

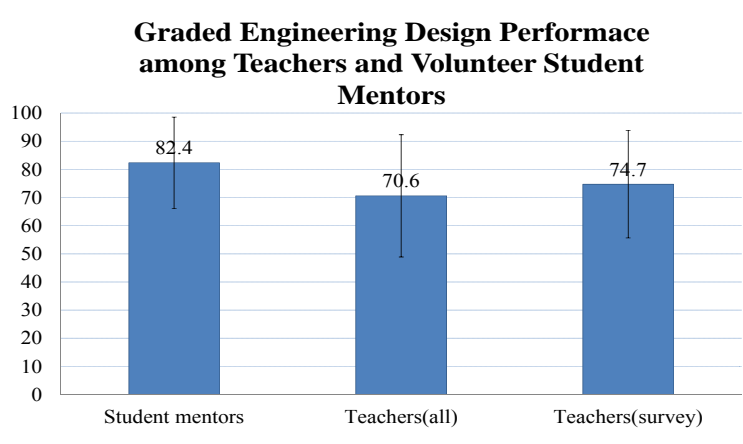

(b)

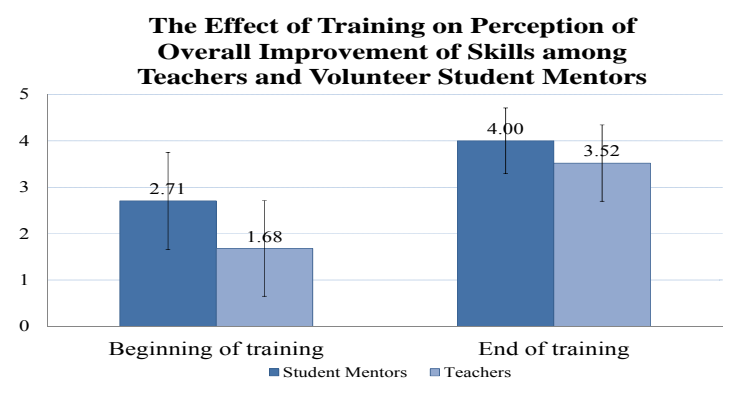

(d)

Figure 3: (a) Average scores and standard deviations of K-12 teachers' self-conceptions toward their belief, motivation, success, and apprehension to perform engineering design and engineering design process; (b) Average graded scores and standard deviations for using engineering design during the final challenge among volunteer student mentors, all participating K-12 teachers, and teachers with survey results shown in part (a); (c) Average perception and standard deviations of attained skills among 17 volunteer student mentors and $25 \mathrm{~K}-12$ teachers after the training; and (d) Average perception and standard deviations of overall improvement of engineering skills among 17 volunteer student mentors and $25 \mathrm{~K}-12$ teachers at the beginning and at the end of the training. 
Table 2: The analysis of graded engineering design performance among teachers with various backgrounds and gender-specific analysis of graded engineering design performance among volunteer mentors and teachers.

\begin{tabular}{|c|c|c|c|c|c|c|}
\hline & \multirow{2}{*}{$n$} & \multirow{2}{*}{ Average } & \multirow{2}{*}{$\begin{array}{l}\text { Standard } \\
\text { Deviation }\end{array}$} & \multirow{2}{*}{$t$-value } & \multicolumn{2}{|c|}{ 95\% Confidence Interval } \\
\hline & & & & & Lower Bound & Upper Bound \\
\hline \multicolumn{7}{|c|}{ Academic background (teachers) } \\
\hline $\begin{array}{l}\text { Science, Technology, } \\
\text { and Math }\end{array}$ & 13 & 78.5 & 17.4 & 2.179 & 68.0 & 89.0 \\
\hline Education & 6 & 52.5 & 23.8 & 2.571 & 27.5 & 77.5 \\
\hline Social Science & 6 & 71.7 & 20.4 & 2.571 & 50.2 & 93.1 \\
\hline \multicolumn{7}{|c|}{ Teaching background (teachers) } \\
\hline Elementary School & 8 & 66.3 & 26.2 & 2.365 & 44.4 & 88.1 \\
\hline Middle School & 6 & 78.0 & 16.2 & 2.571 & 63.5 & 94.9 \\
\hline High School & 9 & 73.3 & 17.4 & 2.306 & 59.3 & 87.3 \\
\hline \multicolumn{7}{|l|}{ Gender (teachers) } \\
\hline Female & 16 & 66.3 & 23.6 & 2.131 & 53.7 & 78.8 \\
\hline Male & 9 & 78.3 & 27.9 & 2.306 & 65.9 & 90.8 \\
\hline \multicolumn{7}{|l|}{ Gender (mentors) } \\
\hline Female & 5 & 83.0 & 15.7 & 2.776 & 63.6 & 100.0 \\
\hline Male & 12 & 82.1 & 17.1 & 2.201 & 72.1 & 93.0 \\
\hline
\end{tabular}

Table 3: Two-sided $t$-test on paired differences between teachers' perceptions of EDP selfefficacy and graded engineering performance, partitioned by academic and teaching backgrounds.

\begin{tabular}{|c|c|c|c|c|c|}
\hline & $n$ & Average differences & $\begin{array}{c}\text { Standard } \\
\text { Deviation }\end{array}$ & $t$-value & Significance \\
\hline Academic background \\
\hline $\begin{array}{c}\text { Science, Technology, } \\
\text { and Math }\end{array}$ & 9 & 15.69 & 21.35 & 2.21 & 0.06 \\
\hline Education & 3 & 24.17 & 26.96 & 1.55 & 0.26 \\
\hline Social Science & 5 & 23.25 & 51.68 & 1.01 & 0.37 \\
\hline Teaching background & 5 & 35.28 & 0.57 & 0.60 \\
\hline Elementary School & 5 & 9 & 31.84 & 1.49 & 0.23 \\
\hline Middle School & 4 & 23.75 & 32.21 & 2.09 & 0.08 \\
\hline High School & 8 & 23.75 &
\end{tabular}




\section{Discussion and Conclusions}

For this study, identical training workshops, which focused on LEGO Mindstorms robot design, construction, and programming, were conducted for NYC volunteer FLL mentors, with mostly STEM backgrounds, and NYC K-12 teachers, with mostly science, technology, mathematics, and social sciences backgrounds. The workshops featured a combination of lectures and hands-on activities to teach robot building and programming skills. To examine the knowledge and skills gained by participants of varied backgrounds, and their potential to implement and sustain LEGO Mindstorms-based K-12 STEM education, the study utilized three types of instruments. The K-12 teachers and volunteer mentors were compared based on their performance in building and programming a robot during the design challenge. The results have shown that, regardless of the background, participants from both volunteer mentor and teacher groups perceived their learning of building and programming skills equally high. The assessment has shown that on average teachers with non-engineering backgrounds perceived improvement of their skills from the workshop to be higher. However, their performance during the final challenge was lower than that of volunteer mentors with engineering background. Teachers who diligently filled out the self-efficacy survey tended to perform slightly better during the design challenge. The self-efficacy analysis has shown that a small sample of teachers with nonengineering backgrounds perceived their self-efficacy and outcome expectancy similar to a larger group of individuals with intermediate self-efficacy reported in Ref. 28.

During the workshops, we observed that the difficulty to perform engineering design for teachers with non-technical background increases with age, however, this informal observation needs to be verified through formal research. Moreover, teachers with non-technical backgrounds were found to have a harder time performing engineering design and learn building and programming concepts. For example, out of 4 teachers who scored themselves to be $\leq 50$ on self-efficacy motivation scale, 3 teachers said that they taught general science, biology, or chemistry or that they were a "Family Associate worker." Moreover, two of these individuals either gave up or showed no effort to participate in building and programming during the final design challenge, and the other two needed additional support in building and programming.

Using statistical analysis tools and by grouping K-12 teachers according to their academic and teaching backgrounds, we discovered that teachers who majored in science, technology, or mathematics performed better at implementing learned skills and conducting engineering design, see Table 2. Moreover, the analysis of Table 2 reveals that high school teachers performed better at engineering design implementation, however this may have resulted because most teachers from this group had science, technology, or mathematics background. The perception of engineering self-efficacy and graded engineering design implementation among high school teachers and those with science, technology and math background were found to be inconsistent, at 10\% significance level. The data analysis for elementary and middle school 
teachers revealed that their perception of self-efficacy and engineering performance were consistent. For the remaining academic groups, there was no significance to reject the null hypothesis that teachers' self-efficacy and engineering design implementation were not consistent. We note that more data should be collected to establish the true significance of background-specific results. Finally, the gender-specific analysis revealed no significant differences between the graded engineering design performance of female versus male participants.

Through this study we have shown that the hurdle of learning LEGO Mindstorms is not excessively high or insurmountable for K-12 teachers with non-engineering backgrounds. Moreover, we found that teachers with science, technology, or math backgrounds are more likely to successfully learn and sustain attained skills during the robot design challenge, compared to teachers without these backgrounds. This may have implications concerning whether teachers lacking science, technology, or math backgrounds can effectively implement and sustain robotics activities in their schools. To enhance teachers' experience in learning robotics, professional development programs may want to consider teachers' educational background and engineering self-efficacy. Specifically, prior to the training, training program organizers may want to divide teachers in separate cohorts based on the age of students they work with or their academic background, however, more data needs to be collected to show the effect of such division. In future work, we hope to develop guidelines to effectively tailor robotic training workshops based on advance knowledge of teachers' self-efficacy so that their learning experience can be enhanced and they can attain greater skills. Moreover, we plan to assess the efficacy of longer duration workshops on teachers' learning and ability to implement LEGO Mindstorms activities in their classroom.

\section{Acknowledgements}

This work is supported in part by the GK-12 Fellows Program of National Science Foundation under grant DGE-0741714: Applying Mechatronics to Promote Science (AMPS). In addition, it is supported in part by the Central Brooklyn STEM Initiative (CBSI), which is funded by the Black Male Donor Collaborative, Brooklyn Community Foundation, J.P. Morgan Chase Foundation, Motorola Innovation Generation Grant, NY Space Grant Consortium, Xerox Foundation, and White Cedar Fund. The authors thank GK-12 Fellows Carlo Yuvienco and Ursula Koniges for conducting a series of workshops; Hussein Saab for videotaping workshops; and Ben Esner and Susan Hermon for advertising and promoting workshops. The authors also thank General Engineering and Mechatronics Laboratories at NYU-Poly and the Mott Hall Bridges Middle School for providing LEGO Mindstorms kits for the robotics workshops. 


\section{References}

[1] Papert, S., Mindstorms: Children, Computers, And Powerful Ideas, Basic Books, New York, NY, 1993.

[2] Appel, K., Gastineau, J., Bakken, C., and Vernier, D., Physics with Computers, Vernier Software and Technology, Beaverton, OR, 2003.

[3] Church, W., Ford, T., Perova, N., and Rogers, C., "Physics with Robotics Using LEGO MINDSTORMS in High School Education," Association for the Advancement of Artificial Intelligence Spring Symposium, Palo Alto, CA, 2010.

[4] Erwin, B., Cyr, M., and Rogers, C., "Lego Engineer and RoboLab: Teaching Engineering with LabView from Kindergarten to Graduate School," International Journal of Engineering Education, 16(3): 181-192, 2000.

[5] Mataric, M.J., Koenig, N., and Feil-Seifer, D., "Materials for Enabling Hands-On Robotics and STEM Education." Proc. AAAI Spring Symposium on Robots and Robot Venues: Resources for AI Education, 2007.

[6] Mukai H., and McGregor, N., "Robot Control Instruction for Eighth Graders," IEEE Control Systems Magazine, 24(5): 20-23, 2005.

[7] Norton, S.J., McRobbie, C.J., and Ginns, I.S., "Problem Solving in a Middle School Robotics Design Classroom," Research in Science Education, 37(3): 261-277, 2007.

[8] Orsak, G. C., Munson, D.C., Weil, A., Conner, M., Rummel, D., "High-Tech Engineering for High School: It's Time!" IEEE Signal Processing Magazine, 21(1): 103-108, 2004.

[9] Pomalaza-Raez, C. and Groff, B.H., "Retention 101: Where Robots Go...Students Follow," Journal of Engineering Education. 92(1): 85-90, 2003.

[10] Rogers, C., and Portsmore, M., "Bringing Engineering to Elementary School." Journal of STEM Education. 5(3): 17-28, 2004.

[11] Wankat, P. and Oreovicz, F., "Gaming the Curriculum," Prism, 15(1): 48, 2005.

[12] Igel, I., Poveda, R., Kapila, V., and Iskander, M., "Enriching K-12 Math Education Using LEGOs," Proc. Amer. Soc. Eng. Ed., Session: T644B. Vancouver, British Columbia, Canada, 2011.

[13] Ortiz, A.M., "Fifth Grade Students' Understanding of Ratio and Proportion in an Engineering Robotics Program," Proc. Amer. Soc. Eng. Ed., Session M444B. British Columbia, Canada, 2011.

[14] Silk, E.M., Higashi, R., Schunn, C.D., "Resources for Robot Competition Success: Assessing Math Use in Grade-School-Level Engineering Design," Proc. Amer. Soc. Eng. Ed., Session M444B. British Columbia, Canada, 2011.

[15] Williams, K., Kapila, V., and Iskander, M., "Enriching K-12 Science Education Using LEGOs," Proc. Amer. Soc. Eng. Ed., Session: T444B. Vancouver, British Columbia, Canada, 2011.

[16] Hsu, M.C., Cardella, M., and Purzer, S., "Elementary Teachers' Perceptions of Engineering and Familiarity with Design, Engineering and Technology: Perspectives from a National Population," Proc. Amer. Soc. Eng. Ed., Louisville, KY: ASEE, 2010.

[17] Guskey, T. R., "Professional Development and Teacher Change," Teachers and Teaching, 8(3): 381391, 2002.

[18] DeLuca D., Robotics and Teaching: Promoting the Effective Use of Technology in Education, Senior Thesis, Department of Child Development, Tufts University, 2003.

[19] Brophy, S., Klein, S., Portsmore, M., and Rogers, C., "Advancing Engineering Education in P-12 Classrooms," Journal of Engineering Education, 97(3): 369-387, 2008.

[20] Katehi, L., Pearson, G., and Feder, M., Engineering in K-12 Education: Understanding the Status and Improving the Prospects, National Academy of Engineering and National Research Council, Washington, DC: National Academies Press, 2009.

[21] Stolkin, R., Hotaling, L., Sheryll, R., Sheppard, K., Chassapis, C., McGrath, E., "A Paradigm for Vertically Integrated Curriculum Innovation-How Curricula were Developed for Undergraduate, Middle and High School Students using Underwater Robotics," Proc. Int. Conf. Engineering Education, Coimbra, Portugal, 2007.

[22] Bratzel, B., Physics by Design with NXT MINDSTORMS, Knoxville, TN: College House Enterprise, 2009.

[23] Church, W., Ford, T., and Perova, N., Physics with Robotics An NXT and RCX Activity Guide For Secondary and College Physics, Knoxville, TN: College House Enterprise, 2009. 
[24] Kee, D., Classroom Activities for the Busy Teacher: NXT, 2008. Available from http://www.domabotics.com.

[25] Bandura, A., "Self-efficacy," in Encyclopedia of Human Behavior, V.S. Ramachaudran (ed.), 71-81, New York: Academic Press, 1994

[26] Bandura, A., Self-efficacy in Changing Societies, New York: Cambridge University Press, 1995.

[27] Bandura, A., Self-efficacy: The Exercise of Control. New York: W.H. Freeman and Company, 1997.

[28] Carberry, A., Ohland, M., and Lee H.-S., "Measuring Engineering Design Self-efficacy," Journal of Engineering Education, 99(1), 71-79, 2010.

[29] Yasar, S., Baker, D., Robinson-Kurpius, S., Krause, S., and Roberts, C., "Development of a Survey to Assess K-12 Teachers' Perceptions of Engineers and Familiarity with Design, Engineering and Technology," Journal of Engineering Education, 95(3): 205-216, 2006.

[30] Baker, D., Krause, S., and Purzer, S.Y., "Developing an Instrument to Measure Tinkering and Technical Self-efficacy in Engineering," Proc. Amer. Soc. Eng. Ed., Pittsburgh, PA, 2008.

[31] Massachusetts Science and Technology/Engineering Curriculum Framework. Malden, MA: Massachusetts Department of Education, 2001/2006.

[32] Pajares, F., Hartley, J., and Valiante, G., "Response Format in Writing Self-efficacy Assessment: Greater Discrimination Increases Prediction," Measurement and Evaluation in Counseling and Development, 33 (4): 214-21, 2001.

[33] Kirkpatrick, D., "Revisiting Kirkpatrick’s Four-level Model.” Train Dev., 50(1):54-59, 1996.

[34] Landis, J.R., Koch, G.G., "The Measurement of Observer Agreement for Categorical Data," Biometrics, 33:159-74, 1977.

[35] Viera A.J., Garrett, J.M., "Understanding Interobserver Agreement: The kappa Statistic,” Fam. Med., 37: 360-363, 2005.

[36] Armitage, P., Berry G., and Matthews, N.S., Statistical Methods in Medical Research, Malden, MA: Wiley-Blackwell, 2001.

[37] Sachs, L., Applied Statistics: A Handbook of Techniques, New York, NY: Springer-Verlag, 1984. 


\section{Appendix A}

Table A1: Background survey and post-evaluation used to collect data for robotics-based workshops.

Please write your initials:

1. What was your major in college or grad school (choose one):

- $\quad$ Arts and Humanities (art, language, pre-law, etc )

- $\quad$ Social Sciences (psychology, political science, sociology, history, etc.)

- Education

- Business

- $\quad$ Engineering

- Science, Technology, or Math

- Other:

2. How long have you been teaching?

- What age of students have you worked with?

- What subject and curriculum did you teach?

3. Have you even been involved in designing, building, or programming robots?

4. Have you ever mentored a robotics team (choose one: Jr. FLL, FLL, FTC, FRC)?

Poor Fair Satisfactory $\quad$ Very Good $\quad$ Excellent

Overall quality of the training

5. Rate overall quality of today's training
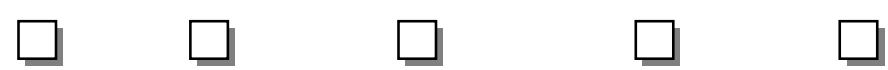

Contribution to learning

6. Your level of skill/knowledge at the start of the training
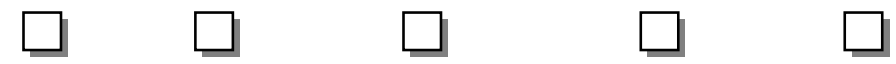

7. Your level of skill/knowledge at the end of the training
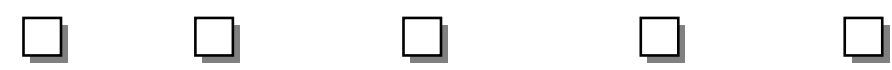

8. The contribution of the training to your robot building skills

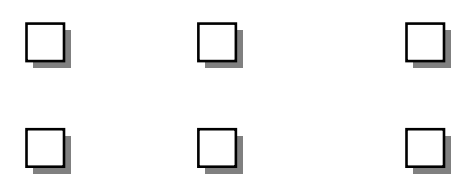

Mindstorms programming skills

Comments: 
Table A2: Engineering design self-efficacy instrument. ${ }^{28}$

Please write your initials:

DIRECTIONS: Please answer all of the following questions fully by selecting the answer that best represents your beliefs and judgment of your current abilities. Answer each question in terms of who you are and what you know today about the given tasks. $(0=10 w ; 50=$ moderate; $100=$ high)

1. Rate your degree of confidence (i.e. belief in your current ability) to perform the following tasks by checking a number from 0 to 100 .

\begin{tabular}{|l|l|l|l|l|l|l|l|l|l|l|l|}
\hline & 0 & 10 & 20 & 30 & 40 & 50 & 60 & 70 & 80 & 90 & 100 \\
\hline conduct engineering design & & & & & & & & & & & \\
\hline identify a design need & & & & & & & & & & & \\
\hline research a design need & & & & & & & & & & & \\
\hline develop design solutions & & & & & & & & & & & \\
\hline select the best possible design & & & & & & & & & & & \\
\hline constuct a prototype & & & & & & & & & & & \\
\hline evaluate and test a design & & & & & & & & & & & \\
\hline communicate a design & & & & & & & & & & & \\
\hline redesign & & & & & & & & & & & \\
\hline
\end{tabular}

2. Rate how motivated you would be to perform the following tasks by checking a number from 0 to 100 .

\begin{tabular}{|l|l|l|l|l|l|l|l|l|l|l|l|}
\hline & 0 & 10 & 20 & 30 & 40 & 50 & 60 & 70 & 80 & 90 & 100 \\
\hline conduct engineering design & & & & & & & & & & & \\
\hline identify a design need & & & & & & & & & & & \\
\hline research a design need & & & & & & & & & & & \\
\hline develop design solutions & & & & & & & & & & & \\
\hline select the best possible design & & & & & & & & & & & \\
\hline constuct a prototype & & & & & & & & & & & \\
\hline evaluate and test a design & & & & & & & & & & & \\
\hline communicate a design & & & & & & & & & & & \\
\hline redesign & & & & & & & & & & & \\
\hline
\end{tabular}

3. Rate how successful you would be in performing the following tasks by checking a number from 0 to 100 .

\begin{tabular}{|l|l|l|l|l|l|l|l|l|l|l|l|}
\hline & 0 & 10 & 20 & 30 & 40 & 50 & 60 & 70 & 80 & 90 & 100 \\
\hline conduct engineering design & & & & & & & & & & & \\
\hline identify a design need & & & & & & & & & & & \\
\hline research a design need & & & & & & & & & & & \\
\hline develop design solutions & & & & & & & & & & & \\
\hline select the best possible design & & & & & & & & & & & \\
\hline constuct a prototype & & & & & & & & & & & \\
\hline evaluate and test a design & & & & & & & & & & & \\
\hline communicate a design & & & & & & & & & & & \\
\hline redesign & & & & & & & & & & & \\
\hline
\end{tabular}

4. Rate your degree of anxiety (how apprehensive you would be) in performing the following tasks by checking a number from 0 to 100 .

\begin{tabular}{|l|l|l|l|l|l|l|l|l|l|l|l|}
\hline & 0 & 10 & 20 & 30 & 40 & 50 & 60 & 70 & 80 & 90 & 100 \\
\hline conduct engineering design & & & & & & & & & & & \\
\hline identify a design need & & & & & & & & & & & \\
\hline research a design need & & & & & & & & & & & \\
\hline develop design solutions & & & & & & & & & & & \\
\hline select the best possible design & & & & & & & & & & & \\
\hline constuct a prototype & & & & & & & & & & & \\
\hline evaluate and test a design & & & & & & & & & & & \\
\hline communicate a design & & & & & & & & & & & \\
\hline redesign & & & & & & & & & & & \\
\hline
\end{tabular}

